\title{
MUCOSAL EOSINOPHILIA- A PROGNOSTIC INDICATOR FOR RECURRENCE IN SINONASAL POLYPOSIS
}

\author{
Niveditha Jayanna1, Vineeth Abraham Anchery²
}

${ }^{1}$ Assistant Professor, Department of ENT and Head and Neck, DM-Wayanad Institute of Medical Sciences and Research Centre, Kerala, India.

${ }_{2}^{2}$ Assistant Professor, Department of ENT and Head and Neck, DM-Wayanad Institute of Medical Sciences and Research Centre, Kerala, India.

\begin{tabular}{l}
\hline ABSTRACT \\
BACKGROUND \\
With the increasing use and availability of modern investigative modalities for diagnosis of nasal polyposis, an increasing number \\
of cases are being diagnosed routinely. Although, a huge number of these patients are subjected to FESS, the post-operative \\
recurrence free period is unpredictable. Many studies have investigated the association of mucosal eosinophilia and the surgical \\
outcome, few studies have considered the level of tissue eosinophil density required to define mucosal eosinophilia.
\end{tabular}

\section{MATERIALS AND METHODS}

A prospective observational study from January 2015 - January 2017 with 100 subjects having massive nasal polyposis was conducted. Pre-operatively, specimen was subjected for histopathological examination to comment on the mucosal eosinophilia. Based on this, subjects were classified into two groups and the results were compared.

\section{RESULTS}

In our study, there was significant relation between recurrence of nasal polyposis and mucosal eosinophilia. Out of the 100 subjects involved in the study, 36 patients fell into Group 1 and 64 patients into Group 2. In Group 2, 20 (31\%) patients had no recurrence and $44(69 \%)$ patients had recurrence which showed a statistical significance of $\mathrm{p}$-value $<0.05$.

\section{CONCLUSION}

The present study found that the level of mucosal eosinophilia of $>10$ eosinophils/ HPF had the greatest impact on disease recurrence.

\section{KEY WORDS}

Mucosal Eosinophilia, Functional Endoscopic Sinus Surgery, Chronic Rhinosinusitis, Sinonasal Polyposis, Diagnostic Nasal Endoscopy, Osteomeatal Complex.

HOW TO CITE THIS ARTICLE: Jayanna N, Anchery VA. Mucosal eosinophilia- a prognostic indicator for recurrence in sinonasal polyposis. J. Evolution Med. Dent. Sci. 2018;7(22):2709-2712, DOI: 10.14260/jemds/2018/610

\section{BACKGROUND}

Sinonasal polyposis occurs as a result of chronic inflammation. After the formation of nasal polyps, they themselves perpetuate inflammatory process. ${ }^{1}$ The prevalence rate is close to $2 \%-4 \%$, which increases with age of the study population. ${ }^{2-4}$ The advances in diagnostic imaging, endoscopy and early consultations due to improved general health awareness among people has all helped in picking up cases at the initial stages of polyposis itself. Over the years, giving credit to widespread availability of endoscopy where many of these can be directly shown to patients has helped in convincing them for surgery. Although, many of the early cases respond to oral and topical corticosteroid therapy, massive polyposis cases invariably will have to be subjected to undergo FESS. It is at this point that surgeon explains a guarded approach on outcome and the fact that there could be a chance of recurrence. Many a times even the symptom- free interval after the procedure could not be

'Financial or Other Competing Interest': None.

Submission 30-03-2018, Peer Review 10-05-2018,

Acceptance 17-05-2018, Published 28-05-2018.

Corresponding Author:

Dr. Niveditha Jayanna,

Department of ENT and Head and Neck,

DM-Wayanad Institute of Medical Sciences

and Research Centre, Wayanad-673577, Kerala, India.

E-mail: niveditha150@gmail.com

DOI: $10.14260 /$ jemds $/ 2018 / 610$ predicted, because recurrence have been noted as early as within few weeks of the operation.

Innumerable number of studies have been done to establish the relationship between asthma, allergy, NSAID intolerance, ciliary dyskinesia to polyposis, but very few to predict the recurrence at least post-operatively. Eosinophil dominated inflammation has been found to be a common feature and of importance in allergic fungal sinusitis and NSAID intolerance. ${ }^{5}$ Because there is a lack of any indicator as to when recurrence occurs in the post-operative period, the length of duration for which post-operative nasal wash and topical corticosteroids to be used is uncertain, if only there was a clue as to which patient to be treated aggressively or for longer duration to prevent recurrence. By subjecting the postoperative specimen for histopathological evaluation, an increased mucosal eosinophilia can be taken as an indicator to find out the probability of recurrence in a patient undergone surgery.

\section{MATERIALS AND METHODS Objective of Study}

To know the relationship between the mucosal eosinophils and recurrence of polyposis and prognosis of the disease.

A prospective observational study of 100 patients who had undergone FESS for massive sinonasal polyposis during January 2015 - January 2017 were conducted. Out of which, 68 were males and 32 were females. The age group extended from 25 - 60 years. The pre-operative investigations like CT 
scan and diagnostic nasal endoscopy were done and sample specimen collected during DNE was subjected to histopathological examination to comment on mucosal eosinophilia. The mucosal eosinophil densities were determined and divided into two groups. Group $1-<10$ eosinophils per HPF and Group 2 - > 10 eosinophils per HPF. The recurrence of nasal polyps in both the groups were compared. Preoperatively, the patients were put on oral and topical steroids for 2 weeks after collecting the sample specimen for HPE. Intraoperatively, middle meatal antrostomy, ethmoidectomy, sphenoidotomy and frontal sinus clearance was done. Postoperatively, tapering doses of oral steroids were given for a month along with isotonic saline wash twice daily and topical steroids. Patients were asked to follow-up after 1 st week, 2nd week, 1 month, 3 months, 6 months, 12 months and 24 months.

\section{Inclusive Criteria}

Massive nasal polyposis.

\section{Exclusive Criteria}

Infective sinusitis, previously operated patient.

\section{Statistical Analysis}

The proportion test (Z-test) was used to compare the percentage of recurrence between the two groups. (The 8 subjects lost during the follow-up were not included in the analysis).

\section{RESULTS}

Demographic characteristics.

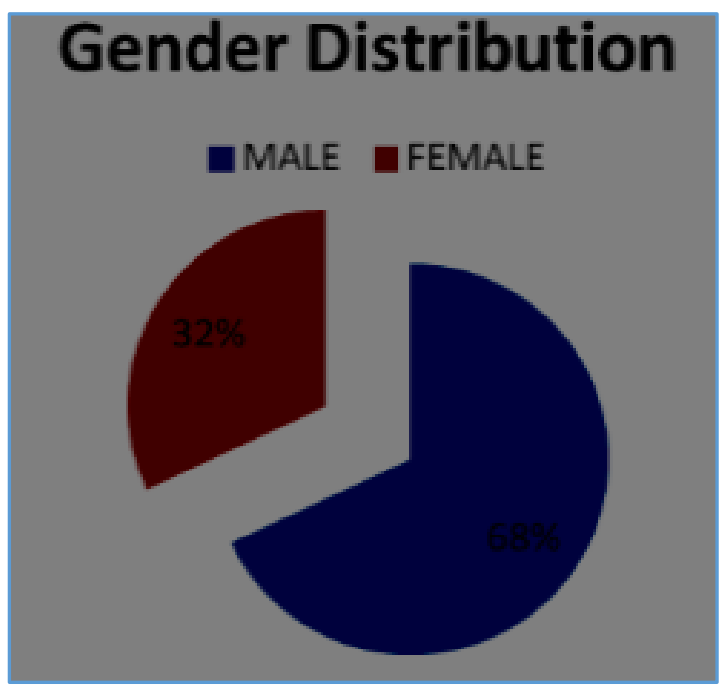

Figure 1. Gender Distribution

Out of the 100 patients studied, 36 patients fell in Group 1 , in which 22 had no recurrence and 16 presented with recurrence during follow-up period of 6 months -24 months.

64 patients were under Group 2, of which 20 had no recurrence and 44 had recurrences from as early as 1 week to 24 months. A total of 8 patients were lost during various stages of follow-up.

\begin{tabular}{|c|c|c|}
\hline Time & $\begin{array}{c}<\mathbf{1 0} / \boldsymbol{\mu m} \mathbf{2}(\text { Group 1) } \\
\text { Total- 16 }\end{array}$ & $\begin{array}{c}\mathbf{1 0} / \boldsymbol{\mu m} \mathbf{2} \text { (Group 2) } \\
\text { Total- 44 }\end{array}$ \\
\hline 1 week & & 6 \\
\hline 2 weeks & & 4 \\
\hline 1 month & & 6 \\
\hline 3 months & 5 & 8 \\
\hline 6 months & 7 & 10 \\
\hline 12 months & 4 & 12 \\
\hline 24 months & Table 1. Number of Recurrence in either \\
group for a Period of 24 Months \\
\hline \multicolumn{2}{|c|}{} \\
\hline
\end{tabular}

The cases which had recurrence from Group 1 were 14 whose mucosal eosinophil count was very close to $10 \mu \mathrm{m} 2$, the cut-off value for Group 1; 8 out of 14 patients in this group has an eosinophil count of $9 \mu \mathrm{m} 2$ and one patient has a count of $8 \mu \mathrm{m} 2$. Noticeably, in Group 2 the 6 patients who presented with recurrence immediately within 1 week had the highest readings of mucosal eosinophilia among the entire sample.

\section{Comparing the Recurrence between the Two Groups}

\begin{tabular}{|c|c|c|c|}
\hline & $\begin{array}{c}\text { Group 1 } \\
(\mathbf{N}=36)\end{array}$ & $\begin{array}{c}\text { Group 2 } \\
(\mathbf{N}=64)\end{array}$ & P value \\
\hline Percentage & 44.4 & 68.75 & $<0.05$ \\
\hline \multicolumn{3}{|c|}{ Table 2. Comparing the Recurrence between the Two } \\
Groups \\
\hline
\end{tabular}

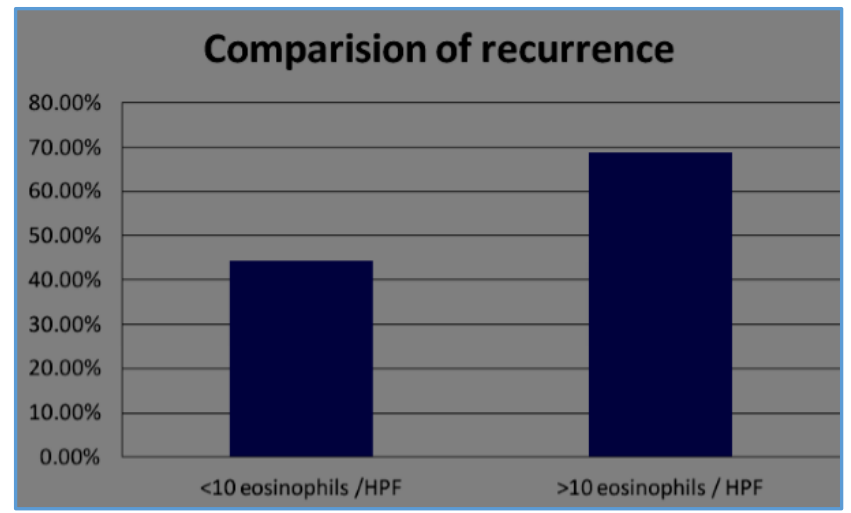

Figure 2. Comparison of Recurrence

Group 1-44.4\% and Group 2- 68.75\%

\section{DISCUSSION}

FESS has a major role in sinus aeration and restoration of mucociliary function through clearance of blocked sinus ostia with a particular focus on OMC disease along with removing disease process, but some patients do not benefit from functional surgery. CRS outcome studies have looked at the relationship between the inflammatory process, disease severity and prognosis, utilising various parameters in an attempt to describe or quantify the degree of inflammation in the mucosa. These parameters include peripheral blood eosinophil count ${ }^{6,7}$ and local mucosal eosinophilic infiltration, expressed as a percentage of inflammatory cells ${ }^{8,9}$ or as an absolute number of eosinophils per high-power field.10-13 Mucosal eosinophilia correlated with disease severity ${ }^{9-13}$ and other studies showed a similar correlation with systemic eosinophil counts.7,12,14,15 Patients with persistent nasal discharge and recurrence of nasal polyps after surgery had a 
significant predomination of eosinophils in their secretions when compared with controls with no polyps. ${ }^{16}$ This eosinophilia was still prominent even in the presence of a positive bacterial culture, a feature that normally gives a neutrophilic skew. ${ }^{16}$ It was found that a higher grade of mucosal eosinophilia consistently predicted a poor prognosis with more probable recurrence of disease,17,18 a higher level of postoperative symptoms ${ }^{19}$ and less improvement in postoperative quality-of-life scores. ${ }^{20,21}$ Similar conclusions were also drawn when serum eosinophilia was studied.17,22 These data illustrate that relieving an obstruction that hinders ventilation and mucociliary clearance is not the only determinate of surgical success; the inflammatory process, in which the eosinophil acts as the pivotal cell is of equal significance in determining long- and short-term prognosis.

Eosinophils are also a main producer of eotaxins ${ }^{23-25}$ and their granule proteins when released stimulate eosinophils themselves to degranulate. ${ }^{26}$ In this way, eosinophils contribute to the persistence of their own species in an autocrine fashion. Moreover, eosinophilic CRS is associated with an increased expression of the glucocorticoid receptor-b isoform. ${ }^{27}$ The glucocorticoid receptor-b is a steroid action inhibitor that is associated with steroid insensitivity. ${ }^{27}$ In addition to infiltration within the mucosa, eosinophils also escape to the mucus produced within the sinus cavity itself 31 with the epithelial production of EM. Antigenic materials (For example- staphylococcal super antigens or fungal remnants) become entrapped in the thick viscous EM and persist locally leading to continuous immune stimulation. EM contains toxic products from degranulated cells and leads to increased migration of eosinophils from the circulation to the nose, suggesting the presence of chemo attractants in the mucus that encourage eosinophil migration. ${ }^{28}$ In this way, EM is not just an end product of disease, but also plays an active role in disease perpetuation.

The main factors of the study are: (1) Their surgical treatments were performed consecutively by the same surgeon; (2) Their histological diagnosis was established by the same pathologist; (3) Their laboratory tests were performed at the same laboratory; and (4) Postoperative medical treatment was standardised.

In our study, there was significant relation between recurrence of nasal polyposis and mucosal eosinophilia. Out of the 100 subjects involved in the study, 36 patients fell into Group 1 and 64 patients into Group 2. In Group 1, 36 (44.4\%) patients and $64(68.75 \%)$ patients had recurrence which showed a statistical significance of $P$ value $<0.05$ as shown in Figure 2 and Table 2 . The present study found that the level of mucosal eosinophilia of $>10$ eosinophils/ HPF had the greatest impact on disease recurrence.

The presence of mucosal eosinophilia is frequently associated with more severe disease and recurrence of nasal polyps after surgery. ${ }^{29}$ Several other studies have investigated the relationship between the number of mucosal eosinophils and surgical outcomes, but few studies have considered the level of tissue eosinophil density required to define mucosal eosinophilia. Considering more recent available data, in 2010 Tosun et $\mathrm{al}^{30}$ analysed 42 patients who had undergone endoscopic sinus surgery for massive nasal polyposis. The eosinophil leukocyte densities in nasal polyps were determined retrospectively on histologic slides by use of computer-assisted image analysis system: eosinophil-rich nasal polyps ( 4 or more eosinophils per $1000 \operatorname{lm} 2$ ) had a higher postoperative recurrence rate. Analysing the results of a prospective study, Nakayama et al concluded that patients with mucosal eosinophilia had higher polyp recurrence rate than patients without mucosal eosinophilia. Very recently, in prospective monocentre study including 96 patients with CRSwNP, Vlaminck et $\mathrm{al}^{31}$ found that CRSwNP patients with tissue eosinophilic involvement showed a recurrence rate of $48 \%$ and those with additional eosinophilic mucin showed recurrence in $56 \%$.

\section{CONCLUSION}

Although, FESS is the current gold standard, the extent of surgery used remains highly variable. Many reports suggest that the eosinophil is the most important predictor of longterm outcome. Patients with a high mucosal eosinophil load have a higher chance of recurrence of polyposis after FESS. The present study indicates that mucosal eosinophilia is a more important prognostic factor than the presence of nasal polyps in terms of the surgical outcome. Hence, this information can be used to sensitise the patient regarding the prognosis in terms of recurrence soon after the arrival of histopathology report and initiate topical steroid therapy soon after surgery. It can also be taken as an indicator to determine the duration of such therapy also, which will be motivating to the patient and helps in patient compliance. This study once again ascertains the fact that FESS only forms a part of the entire management of chronic rhinosinusitis with sinonasal polyposis.

\section{REFERENCES}

[1] Denburg J. Nasal polyposis - cytokines and inflammatory cells. In: Mygind N, Linldholdt T, eds. Nasal polyposis: an inflammatory disease and its treatment. Copenhagen: Munksgaard 1997: p. 78-87.

[2] Settipane GA. Nasal polyps: epidemiology, pathology, immunology and treatment. Am J Rhinol 1987;1(3):119-26.

[3] Mygind N, Lildholdt T, van der Baan B. Epidemiology and natural history. In: Mygind $\mathrm{N}$, Lildholdt $\mathrm{T}$, eds. Nasal polyposis: an inflammatory disease and its treatment. Copenhagen: Menksgaard 1997: p. 13-16.

[4] Hedman J, Kaprio J, Poussa T, et al. Prevalence of asthma, aspirin intolerance, nasal polyposis and chronic obstruction pulmonary disease in a population-based study. Int J Epidemol 1999;28(4):717-22.

[5] Nakayama T, Yoshikawa M, Asaka D, et al. Mucosal eosinophilia and recurrence of nasal polyps - new classification of chronic rhinosinusitis. Rhinology 2011;49(4):392-6.

[6] Staikuniene J, Vaitkus S, Japertiene LM, et al. Association of chronic rhinosinusitis with nasal polyps and asthma: clinical and radiological features, allergy and inflammation markers. Medicina (Kaunas) 2008;44(4):257-65.

[7] Hoover GE, Newman LJ, Platts-Mills TA, et al. Chronic sinusitis: risk factors for extensive disease. J Allergy Clin Immunol 1997;100(2):185-91.

[8] Jankowski R, Bouchoua F, Coffinet L, et al. Clinical factors influencing the eosinophil infiltration of nasal polyps. Rhinology 2002;40(4):173-8. 
[9] Szucs E, Ravandi S, Goossens A, et al. Eosinophilia in the ethmoid mucosa and its relationship to the severity of inflammation in chronic rhinosinusitis. Am J Rhinol 2002;16(3):131-4.

[10] Kountakis SE, Arango P, Bradley D, et al. Molecular and cellular staging for the severity of chronic rhinosinusitis. Laryngoscope 2004;114(11):1895-905.

[11] Soler ZM, Sauer DA, Mace J, et al. Relationship between clinical measures and histopathologic findings in chronic rhinosinusitis. Otolaryngol Head Neck Surg 2009;141(4):454-61.

[12] Newman LJ, Platts-Mills TA, Phillips CD, et al. Chronic sinusitis. Relationship of computed tomographic findings to allergy, asthma, and eosinophilia. JAMA 1994;271(5):363-7.

[13] Bhattacharyya N, Vyas DK, Fechner FP, et al. Tissue eosinophilic in chronic sinusitis: quantification techniques. Arch Otolaryngol Head Neck Surg 2001;127(9):1102-5.

[14] Bryson JM, Tasca RA, Rowe-Jones JM. Local and systemic eosinophilia in patients undergoing endoscopic sinus surgery for chronic rhinosinusitis with and without polyposis. Clin Otolaryngol Allied Sci 2003;28(1):55-8.

[15] Poznanovic SA, Kingdom TT. Total IgE levels and peripheral eosinophilia: correlation with mucosal disease based on computed tomographic imaging of the paranasal sinus. Arch Otolaryngol Head Neck Surg 2007;133(7):701-4.

[16] Bhattacharyya N. The cytology and microbiology of persistent paranasal sinus secretions after endoscopic sinus surgery: a controlled study. Laryngoscope 2007;117(11):2041-4.

[17] Matsuwaki Y, Ookushi T, Asaka D, et al. Chronic rhinosinusitis: risk factors for the recurrence of chronic rhinosinusitis based on 5-year follow-up after endoscopic sinus surgery. Int Arch Allergy Immunol 2008;146(Suppl 1):77-81.

[18] Stoop AE, van der Heijden HA, Biewenga J, et al. Eosinophils in nasal polyps and nasal mucosa: an immunohistochemical study. J Allergy Clin Immunol 1993;91(2):616-22.

[19] Myller JP, Toppila-Salmi SK, Toppila EM, et al. Mucosal eosinophils and l-selection ligands are associated with invasive and non-invasive sinus surgery outcomes. Am J Rhinol Allergy 2009;23(1):21-7.
[20] Smith TL, Litvack JR, Hwang PH, et al. Determinants of outcomes of sinus surgery: a multi-institutional prospective cohort study. Otolaryngol Head Neck Surg 2010;142(1):55-63.

[21] Soler ZM, Sauer D, Mace J, et al. Impact of mucosal eosinophilia and nasal polyposis on quality-of-life outcomes after sinus surgery. Otolaryngol Head Neck Surg 2010;142(1):64-71.

[22] Zadeh MH, Banthia V, Anand VK, et al. Significance of eosinophilia in chronic rhinosinusitis. Am J Rhinol 2002;16(6):313-7.

[23] Molinaro RJ, Bernstein JM, Koury ST. Localization and quantitation of eotaxin mRNA in human nasal polyps. Immunol Invest 2003;32(3):143-54.

[24] Seto H, Suzaki H, Shioda S. Immunohistochemical localization of eotaxin immunoreactivity in nasal polyps. Acta Otolaryngol Suppl 2004;124(553):99104.

[25] Yao T, Kojima Y, Koyanagi A, et al. Eotaxin-1, -2, and -3 immunoreactivity and protein concentration in the nasal polyps of eosinophilic chronic rhinosinusitis patients. Laryngoscope 2009;119(6):1053-9.

[26] Kita H, Abu-Ghazaleh RI, Sur S, et al. Eosinophil major basic protein induces degranulation and IL-8 production by human eosinophils. J Immunol 1995;154(9):4749-58.

[27] Takeda K, Takeno S, Hirakawa K, et al. Expression and distribution of glucocorticoid receptor isoforms in eosinophilic chronic rhinosinusitis. Auris Nasus Larynx 2010;37(6):700-7.

[28] Wei JL, Kita H, Sherris DA, et al. The chemotactic behavior of eosinophils in patients with chronic rhinosinusitis. Laryngoscope 2003;113(2):303-6.

[29] Stjarne P, Olsson P, Alenius M. Use of mometasone furoate to prevent polyp relapse after endoscopic sinus surgery. Arch Otolaryngol Head Neck Surg 2009;135(3):296-302.

[30] Tosun F, Arslan HH, Karslioglu Y, et al. Relationship between postoperative recurrence rate and eosinophil density of nasal polyps. Ann Otol Rhinol Laryngol 2010;119(7):455-9.

[31] Vlaminck S, Vauterin T, Hellings PW, et al. The importance of local eosinophilia in the surgical outcome of chronic rhinosinusitis: a 3-year prospective observational study. Am J Rhinol Allergy 2014;28(3):260-4. 